\title{
TB contact investigations: 12 years of experience in the National TB Programme, Morocco 1993-2004
}

S. Ottmani, ${ }^{1}$ M. Zignol, ${ }^{1}$ N. Bencheikh, ${ }^{2}$ L. Laâsri, ${ }^{2}$ L. Blanc ${ }^{1}$ and J. Mahjour ${ }^{2}$

$$
\begin{aligned}
& \text { التقصّيات حول المخالطين لمرضى السُل: خبرة البرنامج الوطني لمكافحة السُل لمدة } 12 \text { عاماً؛ المغرب }
\end{aligned}
$$

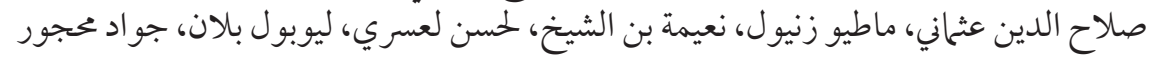

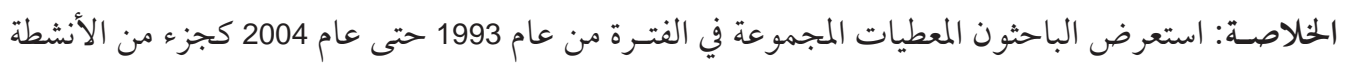

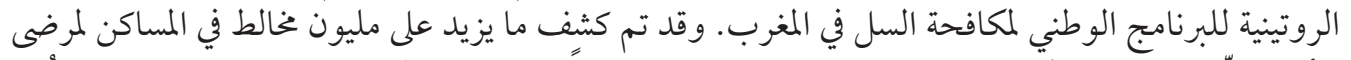

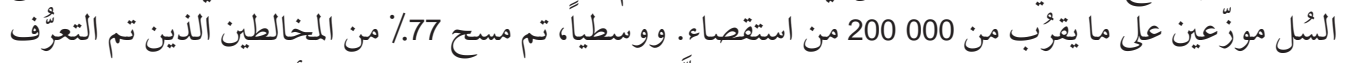

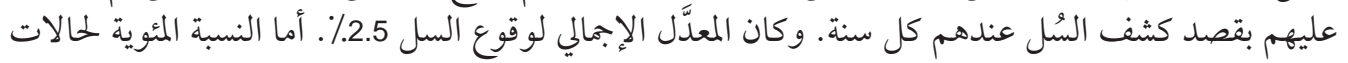

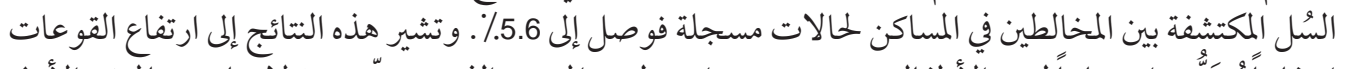

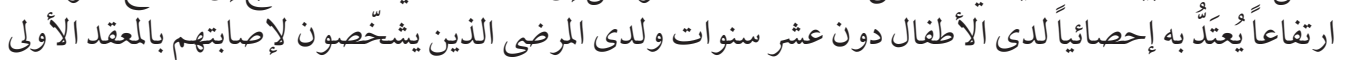

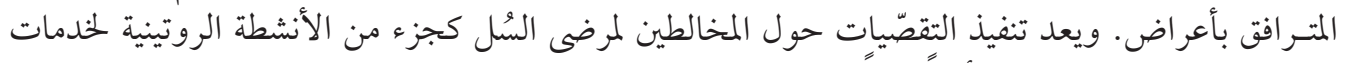

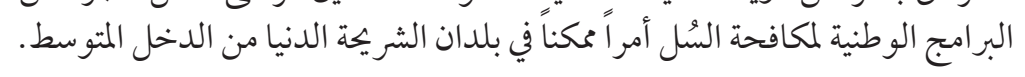

ABSTRACT We reviewed data collected from 1993 to 2004 as part of the routine activities of the national tuberculosis (TB) control programme (NTP) in Morocco. More than 1 million household TB contacts were identified in approximately 200000 investigations. On average, $77 \%$ of identified contacts were screened every year; overall prevalence was $2.5 \%$. The proportion of TB cases identified in household contacts of registered cases was $5.6 \%$. This was significantly higher in children under 10 years and in patients registered and diagnosed with symptomatic primary complex. Performing TB contact investigations as part of the routine activities of NTP services is feasible in low-middle-income countries.

\begin{abstract}
Recherches sur les personnes en contact avec des tuberculeux : les résultats de 12 ans d'expérience dans le programme national de lutte contre la tuberculose du Maroc, 1993-2004

RÉSUMÉ Nous avons analysé les données recueillies de 1993 à 2004 dans le cadre des activités de routine du programme national de lutte contre la tuberculose (PNT) au Maroc. Plus d'un million de sujets en contact à leur domicile avec des personnes atteintes de tuberculose ont été recensés à l'occasion de quelque 200000 recherches. En moyenne, $77 \%$ de ces sujets ont fait l'objet d'un dépistage annuel de la tuberculose ; la prévalence globale de la maladie était de 2,5\%. La proportion de cas de tuberculose dénombrés parmi les sujets en contact à leur domicile avec des cas de tuberculose enregistrés était de 5,6\%. Ce chiffre était significativement plus élevé chez les enfants de moins de 10 ans et chez les patients enregistrés pour lesquels un diagnostic de complexe primaire avait été posé. II est possible de rechercher les sujets en contact avec des personnes atteintes de tuberculose dans le cadre des activités de routine des services du PNT dans les pays à revenu faible et moyen.
\end{abstract}

'Stop TB Department, World Health Organization, Geneva, Switzerland (Correspondence to S Ottmani: ottmanis@who.int).

${ }^{2}$ Direction of Epidemiology and Disease Control, Ministry of Health, Rabat, Morocco.

Received: 25/05/08; accepted 12/11/08

المجلة الصحية لشرق المتو سط، منظمة الصحة العالمية، المجلد الخامس عشر، العدد ب، 9 +. 


\section{Introduction}

Tuberculosis (TB) is generally diagnosed by performing clinical, bacteriological, and/ or radiological investigations in persons who present with symptoms or signs suggestive of TB [1], or by screening high risk groups such as people living with human immunodeficiency virus (HIV) or those who have been exposed to TB transmission by being in close contact with an infectious TB case.

Tracing, identifying, and investigating individual contacts of infectious TB cases is a time-consuming exercise that is largely conducted on routine basis only in countries with high resources and low TB prevalence. In resource-limited settings, TB contact investigations are often documented only in the framework of research studies with usually limited number of contacts evaluated.

Morocco is a low-middle-income country where the DOTS strategy to control TB recommended by the World Health Organization (WHO) has been successfully implemented since 1991 [2] and the global targets set up by the World Health Assembly for the year 2005 [3] were achieved by 1995 and have been maintained since that time [4]. In 2005, the notified incidence of all forms of TB was 83 cases $/ 100000$ population and incidence of sputum smearpositive pulmonary TB (SSPPT) was 41 cases/100 000 population, with a detection rate for SSPPT of over 95\% [5].

In Morocco, TB is principally diagnosed through evaluation of persons who present with symptoms or signs suggestive of TB; investigation of persons found to be HIVpositive; and investigation of close contacts of specific categories of cases with TB.

The objective of this study was to report the outcomes of TB contact investigation activities carried out on routine basis by the National TB Control Programme (NTP) of
Morocco from 1993 to 2004, the latest year for which data are available.

\section{Methods}

In this retrospective study the results of all contact investigations performed by the NTP during the period 1993-2004 were analysed. In Morocco, TB contact identification and investigation are performed routinely in each province and prefecture and the results are reported to the central unit of the NTP on an annual basis [6] (although DOTS was implemented in 1991, data on contact investigations were only included in the annual report from 1993).

The procedures for conducting TB contact investigations in Morocco are defined in the NTP guidelines [7]. A TB index case, i.e. the person around whom contact investigation should be carried out, is defined as any case with SSPPT or with symptomatic primary complex (SPC). A patient with SPC is defined as a patient who presents with clinical symptoms compatible with $\mathrm{TB}$, hilar or inter-bronchial lymph nodes with or without lung infiltrates on the chest $\mathrm{X}$-ray, and a positive tuberculin skin test. Recent contact with a patient with active TB and/or young age are additional arguments for the diagnosis of SPC. Patients with SPC are sputum smear-negative and treated using category III treatment regimen (2RHZ/4RH) [7].

TB contact is defined as any person living in the same household as the index case at the time of diagnosis.

For each index case, a list of all household contacts is established by the NTP services. Household contacts are then contacted through the health post network, itinerant nurses, or social workers, and systematically invited to undergo clinical examination and chest $\mathrm{X}$-ray. If TB contacts

المجلة الصحية لشرق المتوسط، منظمة الصحة العالمية، المجلد الخامس عشر، العدد ب، 9 +. 
are children aged under 10 years, a tuberculin skin test is performed in addition to the clinical examination and chest X-ray.

If any clinical sign and/or radiological abnormality suggestive of TB are documented, the person is requested to provide 3 sputum samples for smear microscopy examination. In line with the NTP guidelines [7], a sputum specimen is collected on the spot; then the contact is given a sputum container to collect an early morning specimen at home. The following day, at the time the household contact brings the early morning specimen to the health facility, a third specimen for sputum smear examination is taken.

Cases of TB identified during contact investigations are registered in one of the following categories according to the diagnosis: SSPPT, sputum smear-negative pulmonary TB (SSNPT), extrapulmonary TB (EPT) or SPC. These cases are classified, treated and monitored like all the other TB patients identified from persons who presented to the health facilities with symptoms or signs suggestive of TB.

Children below 5 years of age are systematically provided with isoniazid chemoprophylaxis $(5 \mathrm{mg} / \mathrm{kg}$ daily for 6 months) if no active TB is diagnosed.

The indicators used to assess the outcome of household TB contact investigation are: proportion of identified household contacts screened for TB; prevalence of active TB among the contacts screened; and proportion of active TB identified in household contacts among all TB cases registered.

The chi-squared test was used to assess the statistical significance of the difference between 2 proportions; the Fisher exact test was used whenever an expected number was below 5 in any cell of a $2 \times 2$ contingency table. A test result was considered statistically significant when the $P$-value was $<0.05$.
Ethical approval was not required because this study was retrospective, using aggregated information collected on a routine basis by the NTP.

\section{Results}

From 1993 to 2004, more than 200000 household investigations were carried out by the NTP services of Morocco (Table 1). These investigations identified 1023323 household TB contacts (5.1 identified contacts per investigation); among them 787683 were screened for active TB. In the 1990 s, the number of household TB contacts identified every year was over 90000 . Since the year 2000, this number has progressively decreased, reaching 50257 in 2004 (Table 1). However, the proportion of household contacts screened per year remained more or less stable (overall $77.0 \%$; range: $67.8 \%-82.0 \%$ ). The ratios of household contacts screened per investigation also remained stable over the study period (average: 4.0 contacts screened per investigation; range: 3.2-4.6) (Table 1).

Between 1993 and 1999 the number of contact investigations exceeded the number of cases notified with SSPPT or with SPC around whom contact investigations should be carried out. From 2000 the number of household contact investigations was lower than the number of cases of SSPPT or SPC notified (Figure 1).

The prevalence of any form of TB among households screened remained stable, ranging between $1.9 \%$ and $3.7 \%$ over the 12 years (overall 2.5\%) (Table 2). A similar trend over time was observed for the prevalence of SSPPT, SSNPT, EPT and SPC.

The prevalence of any form of TB tended to be higher among contacts aged $\geq 10$ years than among younger contacts, although important variations between years 


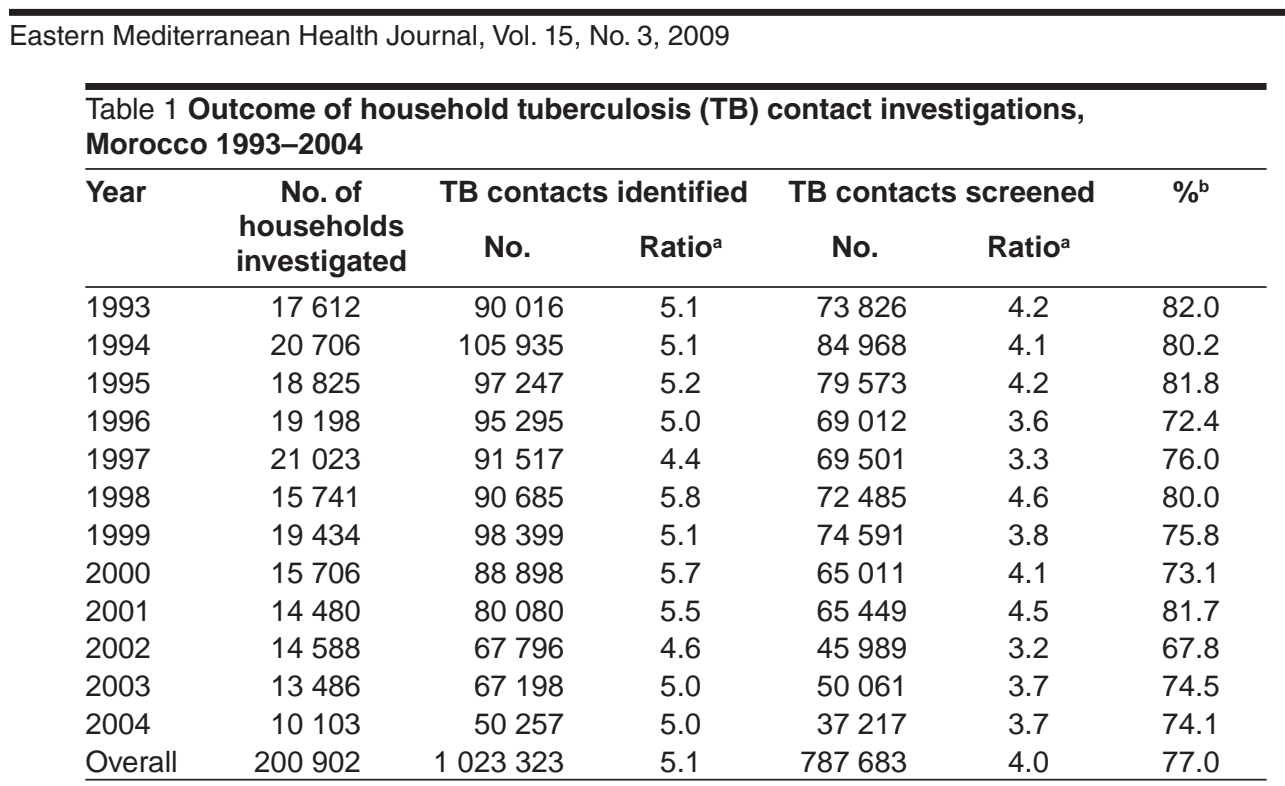

${ }^{a}$ No. per household investigated.

${ }^{b}$ Percentage of TB contacts screened among TB contacts identified.

were observed. The prevalence of SSPPT, SSNPT and EPT was more often significantly higher among contacts aged $\geq 10$ years than among those aged $<10$ years. In contrast, the prevalence of SPC was always significantly higher in those aged $<10$ years (Table 2).

Between $3 \%$ and $10 \%$ of all TB cases (any form) registered during the study period were identified among household contacts. Similar proportions were observed among the SSPPT and SSNPT cases registered, while those for EPT tended to be lower (Table 3). The overall proportions of cases identified in contacts among those registered with any form of TB, SSPPT, SSNPT and EPT were 5.6\%, 5.6\%, 6.5\% and $3.1 \%$ respectively. However among the SPC cases registered during the study period, $27.0 \%$ on average (range $18 \%-34.7 \%$ ) were identified annually among household contacts (Table 3 ).

The stratification by age group shows that the proportion of TB cases identified in household contacts among registered cases was much higher in patients aged $<10$ years in comparison to those aged $\geq 10$ years. This difference was statistically significant for all years among those registered with any form of TB, SSPPT and EPT, and for most of the years among patients with SPC. Almost $20 \%$ of the patients aged $<10$ years who were registered for any form of TB between 1993 and 2004 were identified through household contact investigations (Table 3).

\section{Discussion}

The cumulative number of contacts investigated (787 683 over 12 years) is enormous and far exceeds the size of the largest studies published in the medical literature, ranging from about 1750 to over 3000 [8-11].

The number of households investigated was consistently over 15000 per annum between 1993 and 2000, then decreased significantly from 15706 in 2000 to 10103 in 2004 (Table 1). This decrease cannot 


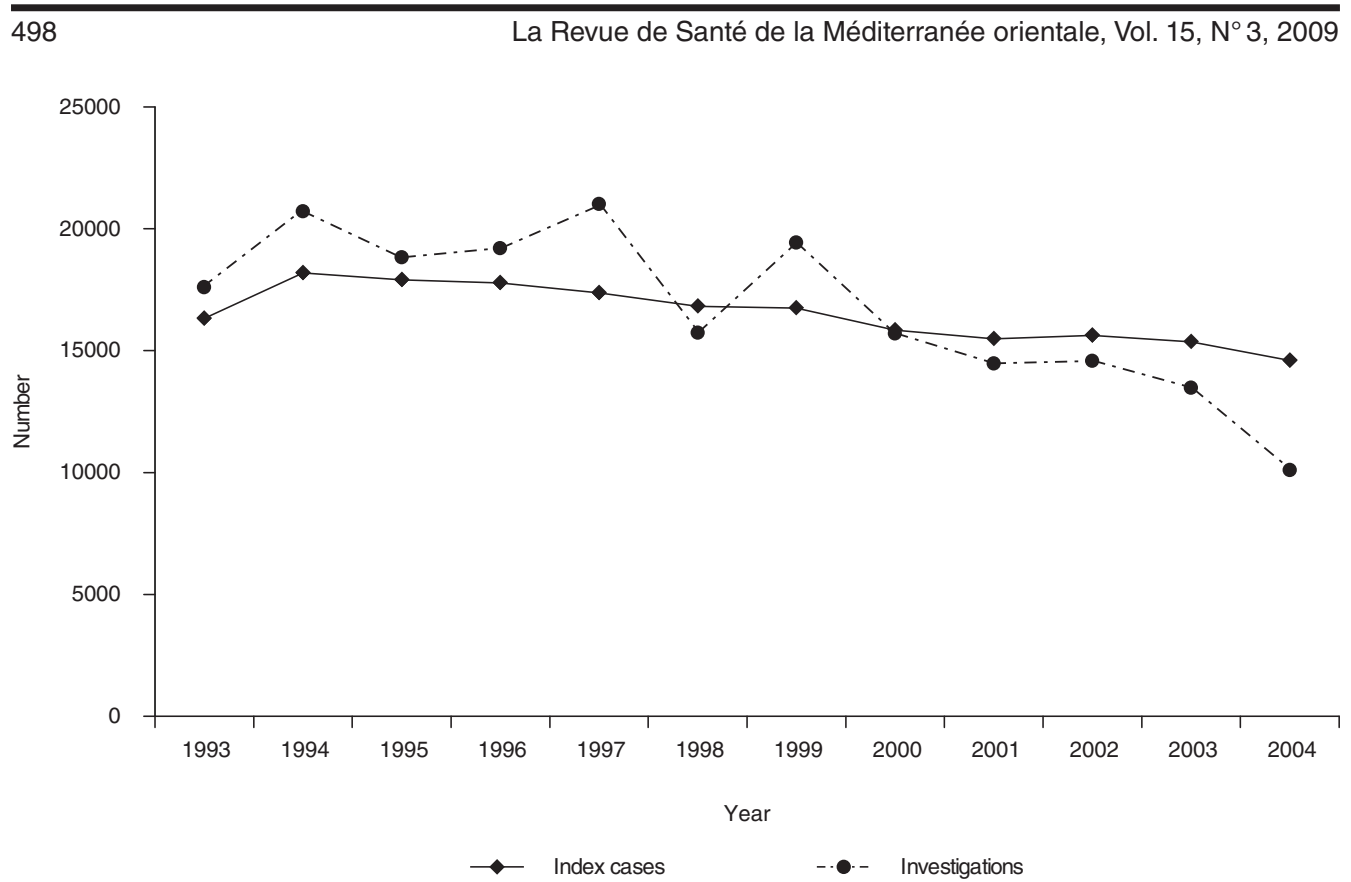

Figure 1 Number of index cases and contact investigations by year, Morocco 1993-2004

be solely explained by the slow decrease in the burden of the disease in Morocco [12]. In fact, further analysis shows that the number of households investigated usually exceeded the number of index cases for whom contact investigations needed to be undertaken between 1993 and 1999. This suggests that in that period the NTP services in some provinces considered as index cases not only SSPPT and SPC, as recommended in the NTP guidelines, but also SSNPT and/or EPT. Before the implementation of DOTS services in 1991, contact investigation was undertaken for any form of TB, including EPT; when the NTP adopted the new strategy, SSNPT and EPT cases were no longer considered index cases. Some provinces continued to use the old definition of index case after the introduction of the DOTS strategy. Between 2000 and 2003, the new definition of index cases started to be used across all provinces.
The number of household investigations became slightly lower than the number of index cases, which is quite acceptable given that some index cases can be clustered in the same household (Figure 1). However, in 2004, the number of households investigated was much lower than expected. This was due to the fact that the NTP services of the provinces of Larache and Fès did not report the findings of their household contact investigation activities carried out over that year. In 2004, the number of index cases identified in these 2 provinces accounted for $8.3 \%$ of the total number of index cases in Morocco [6].

The fact that the definition of index case adopted in 1991 took some time to be fully used in all provinces may have introduced some heterogeneity in the data. This may limit the possibility of appropriately assessing the outcomes of contact investigation over time. Fair assessment would have 


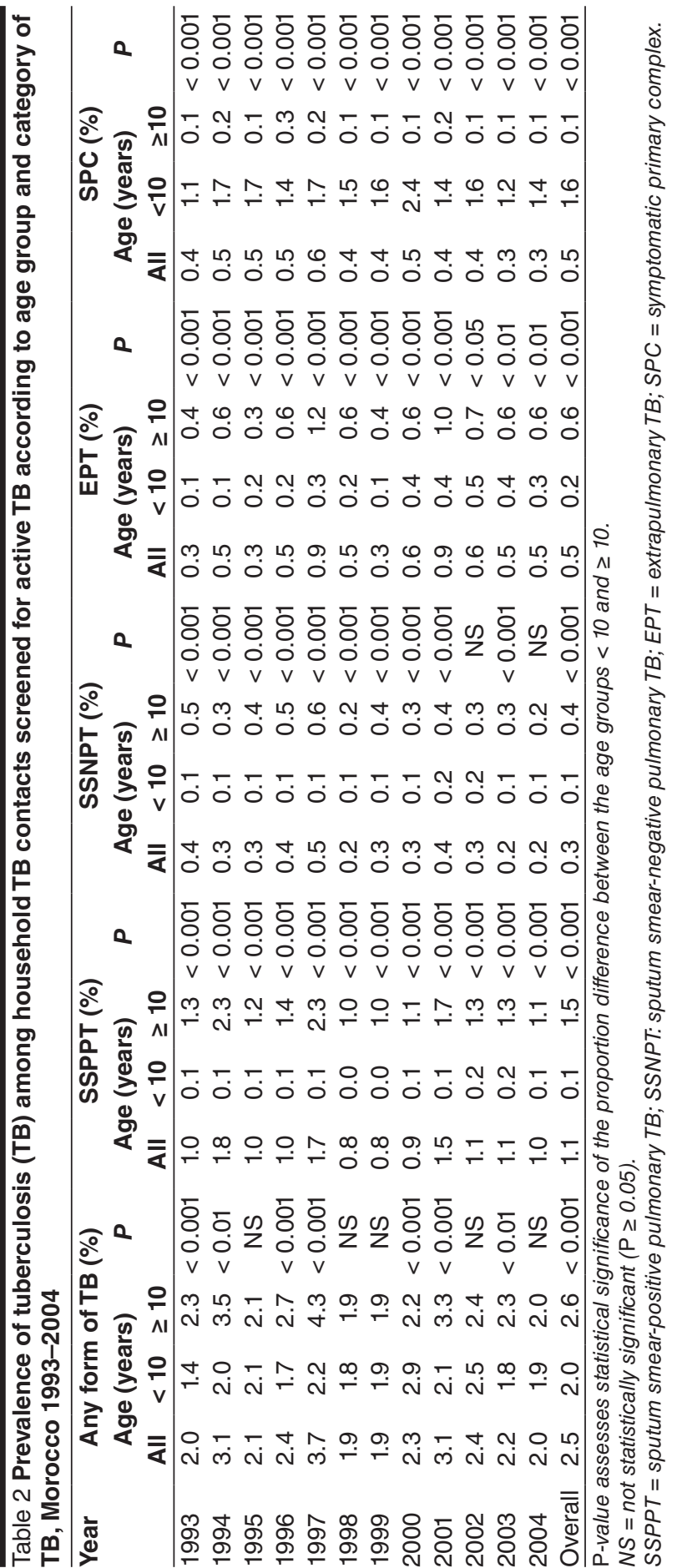

been possible if the data on the outcome of contact investigation were compiled at the national level by type of index case (i.e. SSPPT and SPC).

The study findings suggest that the NTP services need to routinely monitor how the guidelines are applied in the field, collect and compile the information by type of index case, and regularly analyse the data on contact investigation activities in order to take appropriate action.

In Morocco, TB contact investigation in households was a component of the routine activities carried out by the NTP services for many years before the implementation of DOTS. This study shows that a significant proportion of household contacts identified by the NTP services is screened (overall: $77.0 \%$ ). This result was consistent throughout the study period, showing that performing contact tracing is feasible and sustainable in a limitedresource country setting.

Contrary to what happened with the definition of index case $[7,13]$ the definition of TB contact (household members) did not change over the study period and across provinces. This allows for making comparisons between provinces as well as assessing trends over time of the outcome of contact investigation activities. It is important to note that, as per national guidelines, chest $\mathrm{X}$-ray is used in TB screening free of charge for all contacts. Chest $\mathrm{X}$-ray is felt to be an important incentive which made it possible 
to achieve high screening rates among household contacts over many years. It is likely that if no chest X-ray was offered a much lower proportion of household contacts would have presented for screening.

The experience from Morocco shows that screening the closest contacts is highly effective. If all household contacts were screened every year, the proportions identified would likely be higher; our estimate for the overall proportion of TB cases (any type) identified in contacts among all registered TB patients would be $7.3 \%$ instead of $5.6 \%$. Even though the proportion of SPC cases identified in contacts among all registered SPC patients is high, the number of SPC cases accounted for a small proportion among all registered TB cases; their percentage steadily decreased from 5.5\% in 1993 to $1.9 \%$ in 2004 (6). By limiting contact investigations to households, only a few TB cases among other types of contacts, such as schoolmates or workmates, are likely to be missed [14]. To reach them, large amounts of resources are needed for a (very probably) modest yield [15].

The prevalence of each type of TB among household contacts did not vary very much across the years even though in some provinces all TB cases were considered index cases from 1993 to 1999. On average, the prevalence of TB (any type) among household contacts was $2.5 \%$, in line with the findings reported in most of the literature $(2 \%-4 \%)[10,16-19]$,

المجلة الصحية لشرق المتوسط، منظمة الصحة العالمية، المجلد الخامس عشر، العلد ب، 9 + •r 
although a few studies have reported higher figures, $8 \%[20,21]$.

The prevalence of TB (any type) among household contacts was several fold higher than in the general population; for instance, it was 21 times and 19 times higher in 2003 and 2004 respectively [4]. Our data also clearly show that a non-negligible proportion of TB cases aged $<10$ years is identified through household contact investigations. Our findings suggest that the implementation of such activity has a good yield in this age group, particularly regarding SSPTB, $11.1 \%-39.6 \%$, and SPC, $25.3 \%-42.4 \%$ (Table 3 ). As already highlighted in a previous study, the yield for contact investigations is higher among the young and for SPC [22]. Early diagnosis and treatment of SPC could prevent the occurrence of major events such as miliary TB or TB meningitis, particularly in children.

Even though most of the NTPs worldwide consider contact investigation important for TB control, this activity is rarely properly implemented, supervised, evaluated or documented in resource-limited settings. WHO recommends that at least children under 5 years of age and HIVpositive persons who are household contacts of SSPPT cases should be screened for $\mathrm{TB}$ and systematically provided with isoniazid chemoprophylaxis if no active TB is identified [23,24]. However, the definition of index case and TB contact are not clear, and no guidelines exist describing the procedures to be used for screening and follow-up of contacts or specifying the modalities to monitor, evaluate and document investigation activities.

The NTP in Morocco succeeded in building its contact investigation system within routine TB control services because clear national guidance was developed and implemented.

Standardization of definitions and clear recommendations for contact investigation are urgently needed in order to assist countries to set up contact tracing and management procedures, adapt and develop policies and national approaches for contact investigations, and ultimately be able to compare the findings of such activity within and between countries.

Contact investigation is an intervention designed to control and ultimately eliminate TB [25] and it has been shown to be a cost-effective in high-income and low TB prevalence countries [26]. The experience from Morocco shows that conducting contact investigations routinely and under programme conditions is feasible in a low-middle-income country with a relatively high incidence of TB and that an appropriate information system is needed to be able to document the performance of such exercise.

Unfortunately no economic evaluation to determine the cost-effectiveness of contact investigation activities has been conducted in low-income settings. Such an evaluation would be extremely useful for NTPs that plan to introduce contact investigations as part of the routine activities of the programme.

\section{References}

1. Treatment of tuberculosis: guidelines for national programmes. Geneva, World Health Organization, 2003 (WHO/CDS/ TB/2003.313).

2. Ottmani $\mathrm{S}$ et al. La tuberculose et la lutte antituberculeuse au Maroc de 1980 à
1998. Bulletin épidémiologique, 1998 , 35:2-12.

3. Forty-fourth World Health Assembly. Resolutions and decisions. Geneva, World Health Organization, 1991 (Resolution WHA 44.8).

المجلة الصحية لشرق المتوسط، منظمة الصحة العالمية، المجلد الخامس عشر، العدد ؟، 9 . ب 
4. Global tuberculosis control. Geneva, World Health Organization, WHO Reports 1997 (WHO/TB/97.225), 1998 (WHO/TB/98.237), 1999 (WHO/CDS/ CPC/TB/99.259), 2000 (WHO/CDS/TB/ 2000.275), 2001 (WHO/CDS/TB/2001. 287), 2002 (WHO/CDS/TB/2002.295), 2003 (WHO/CDS/TB/2003.316), 2004 (WHO/HTM/TB/2004.331), 2005 (WHO/ HTM/TB/2005.349), 2006 (WHO/HTM/ $\mathrm{TB} / 2006.362)$.

5. Global tuberculosis control: surveillance, planning, financing. Geneva, World Health Organization, 2007 (WHO/HTM/ TB/2007.376).

6. Rapports annuels du programme national de lutte anti-tuberculeuse; années 1993 à 2004. Direction de l'epidémiologie et de lutte contre les maladies. Rabat, Ministry of Health, 1993-2004.

7. Guide de la lutte anti-tuberculeuse à l'usage des professionnels de santé. Rabat, DELM, Ministry of Health, 2001.

8. Narain R et al. Distribution of tuberculous infection and disease among households in a rural community. Bulletin of the World Health Organization, 1966, 34:639-54.

9. Wares DF et al. Is TB contact screening relevant in a developing country setting? Experiences from eastern Nepal, 19961998. International journal of tuberculosis and lung disease, 2000, 4:920-4.

10. Claessens NJM et al. High frequency of tuberculosis in households of index TB patients. International journal of tuberculosis and lung disease, 2002, 6:266-9.

11. Saunders LD, Irwig LM, Wilson TD. Tuberculosis management in Soweto. South African medical journal, 1984;66(9):3303.

12. Dye $\mathrm{C}$ et al. The decline of tuberculosis epidemics under chemotherapy: a case study in Morocco. International journal of tuberculosis and lung disease, 2007, 11(11):1225-31.
13. Guide de la lutte anti-tuberculeuse. Rabat, DELM, Ministry of Public Health, 1996.

14. Genewein A et al. Molecular approach to identifying route of transmission of tuberculosis in the community. Lancet, 1995, 342:841-4.

15. Veen J. Microepidemics of tuberculosis: the stone-in-the-pond principle. Tubercle and lung disease, 1992, 73(2):73-6.

16. Kumar RA et al. Pulmonary tuberculosis among contacts of patients with tuberculosis in an urban Indian population. Journal of epidemiology and community health, 1984; 38(3):253-8.

17. Espinal MA et al. Infectiousness of $\mathrm{Myco-}$ bacterium tuberculosis in HIV-1-infected patients with tuberculosis: a prospective study. Lancet, 2000, 355(9200):275-80.

18. Teixeira $L$ et al. Infection and disease among household contacts of patients with multidrug-resistant tuberculosis. International journal of tuberculosis and lung disease, 2001, 5(4):321-8.

19. Andrews $\mathrm{RH}$ et al. Prevalence of tuberculosis among close family contacts of tuberculous patients in South India, and influence of segregation of the patient on the early attack rate. Bulletin of the World Health Organization, 1960, 23:463-510.

20. Kritski AL et al. Transmission of tuberculosis to close contacts of patients with multidrug-resistant tuberculosis. American journal of respiratory and critical care medicine, 1996, 153(1):331-5.

21. Bayona $\mathrm{J}$ et al. Contact investigations as a means of detection and timely treatment of persons with infectious multidrug-resistant tuberculosis. International journal of tuberculosis and lung disease, 2003, 7(12 Suppl. 3):S501-9. 
22. Beyers $\mathrm{N}$ et al. A prospective evaluation of children under the age of 5 years living in the same household as adults with recently diagnosed pulmonary tuberculosis. International journal of tuberculosis and lung disease, 1997, 1(1):38-43.

23. Interim policy on collaborative TB/HIV activities. Geneva, World Health Organization, 2004 (WHO/HTM/TB/2004.330).

24. Guidance for national tuberculosis programmes on the management of tuberculosis in children. Geneva, World
Health Organization, 2006 (WHO/HTM/ $\mathrm{TB} / 2006.371)$.

25. Rieder HL. Interventions for tuberculosis control and elimination. Paris, International Union Against Tuberculosis and Lung Disease, 2002:1-251.

26. Dasgupta $\mathrm{K}$ et al. Comparison of costeffectiveness of tuberculosis screening of close contacts and foreign-born populations. American journal of respiratory and critical care medicine, 2000, 162:207986.

\section{WHO Report 2009. Global tuberculosis control. Epidemiology, strategy, financing}

The WHO Report 2009 is WHO's thirteenth annual report on global tuberculosis (TB) control in a series that started in 1997. It presents WHO's latest assessment of the epidemiological burden of TB (numbers of cases and deaths), as well as progress towards the 2015 targets for global TB control that have been established within the context of the Millennium Development Goals. It also includes a thorough analysis of implementation and financing of the WHO's Stop TB Strategy and the Stop TB Partnership's Global Plan to Stop TB, since in combination these have set out how TB control needs to be implemented and funded to achieve the 2015 targets. The report gives particular attention to the period 2006-2009, but selected epidemiological, implementation and financial data are presented for previous years as well.

Bringing together data reported by 196 out of 212 countries and territories in 2008, as well as data collected from these countries and territories in previous years, Global tuberculosis control 2009 is the definitive source of information about the national and international response to the worldwide TB epidemic.

المجلة الصحية لشرق المتو سط، منظمة الصحة العالمية، المجلد الخامس عشر، العدد ب، 9 . ب 